\title{
Study of Shelflife of Carrier Biofertilizers from Different Production Centers
}

\author{
K. Bhavya, R. Subhash Reddy, S. Triveni, K. Damodara Chari and Y. Nagaraju** \\ Department of Agricultural Microbiology and Bioenergy, College of Agriculture, Professor \\ Jayashankar Telangana State Agricultural University, Rajendranagar, Hyderbad-30, India \\ *Corresponding author
}

\section{A B S T R A C T}

Keywords

Biofertilizer, Production, Quality, Experiment

Article Info

Accepted:

23 May 2017

Available Online:

10 June 2017
In the present experiment different carrier based Biofertilizers are brought from different firms for evaluation of their quality. In case of carrier based Biofertilizers, population of beneficial bacteria was estimated. The shelf life of biofertilzers was estimated using suitable media for viable count. Microbial population of beneficial bacteria was monitored in carrier based Biofertilizers at monthly intervals. In Carrier based Biofertilizers viable count was constant for three months but a gradual decrease was observed in fourth and fifth months. In carrier based Biofertilizers, the quality was too low, decrease in count was more.

\section{Introduction}

India is an agricultural based country. In order to feed the ever growing populations, India has to increase the per unit area productivity. According to united Nations Food and Agriculture Organization (FAO) estimations, the average demand for the agricultural commodities will be $60 \%$ higher in 2030 than present time and more than $85 \%$ of this additional demand will be from developing countries, for over half a century, the world has relied on the concept of increasing crop yields to supply an ever increasing demand of food. Therefore, vertical expansion of food production is necessary. In order to increase the unit area productivity of agricultural land, the role of different crop nutrients in contributing increased crop yields is vital. Among the crop nutrients, nitrogen as well as phosphorus plays an important role in increasing the productivity. In the last century, chemical fertilizers were introduced and this made farmers to be happy of getting increased yield in agriculture in the beginning. But slowly chemical fertilizer started displaying their ill effects such as leaching, polluting water basins, destroying microorganisms and friendly insects, making the crop more susceptible to the attack of diseases, reducing the soil fertility and thus causing irrepairable damage to the overall system.

One of the other most important effective factors in increasing plant yield with seed inoculation or priming with plant growth promoting rhizobacteria (PGPR) (Ashrafi and Seiedi, 2011). Also, plant growth promoting rhizobacteria (PGPR) are a group of bacteria 
that actively colonize plant roots and increase plant growth and yield (Subbarao 1999; Wu et al., 2005; Heidari et al., 2011).

Carrier based Biofertilizers (CBF) are not so tolerant to the temperature which is mostly unpredictable and uncertain in the crop fields while temperature tolerance is the other advantage of the liquid Biofertilizers (Kumaresan and Reetha 2011). The range of possible contamination is very high as bulk sterilization does not provide the desirable results in the case of carrier based Biofertilizers, whereas the contamination can be controlled constructively by means of proper sterilization techniques and maintenance of intensive hygiene conditions by appropriate quality control measures in the case of liquid based biofertilizer.

Rhizobium and PSB inoculants are often exposed to unfavourable stresses when inoculated seed were planted in the soil. These stresses include such things as low or high $\mathrm{pH}$, high temperature, low moisture and high salt concentrations. Therefore, the Rhizobia and PSB inoculants should be tolerant to these stresses (Liu et al., 2009), have protecting materials in the inoculants formulation or have adaptive mechanisms that increase their tolerance. Adaptive tolerance is a homeostasis mechanism that allows bacteria to survive and grow after sudden changes in environmental conditions. Therefore, the Rhizobium and PSB inoculants for this region should have adaptive tolerance response to low $\mathrm{pH}$ conditions. The formulated liquid inoculants will overcome many of such unexpected adverse environmental factors.

\section{Materials and Methods}

\section{Equipment and apparatus used}

Hot air oven and autoclaves were used for sterilization of heat stable and media respectively. BOD incubators were used for incubating cultures at different temperatures. Cultures were stored and maintained in a refrigerator. The $\mathrm{pH}$ was measured by using digital $\mathrm{pH}$ meter. Cyclomixer was used for homogenization during serial dilution. Plate mixer was used for spread plate technique. Centrifuge was used for making cell-free cultures. Samples were weighed using a single pan electric balance. Compound electron microscope was used to observe the morphology of bacterial cultures. Quebech colony counter was used for counting the viable population of microorganisms.

\section{Microbial analysis of biofertilizers}

The Biofertilizers collected were analyzed for viable population of microorganisms i.e., Rhizobium, Phosphate solubilizing bacteria by the standard serial dilution plate count method (Vlassak et al., 1992) and plating on selective media as mentioned above.

Plates were incubated at $28 \pm 2{ }^{\circ} \mathrm{C}$ in an incubator in triplicates. The microbial colonies appearing after the stipulated time period of incubation were counted as Colony forming units per gram $\left(\mathrm{Cfu} \mathrm{g}^{-1}\right)$ fresh weight of the sample in the colony counter. For analysis of Rhizobium Biofertilizer, $0.1 \mathrm{ml}$ from dilutions such as $10^{-3}$ to $10^{-6}$ were taken and plated on YEMA plates. Whereas for phosphate solubilizing bacterial biofertilizer, $0.1 \mathrm{ml}$ from dilutions such as $10^{-3}$ to $10^{-6}$ were taken and spreaded on Pikovskaya's Agar medium.

To evaluate the quality shelf life of carrier based Biofertilizers.

\section{Collection of biofertilizers}

Different types of carrier based Biofertilizers were collected from following different firms and stored at $4^{\circ} \mathrm{C}$ in refrigerator. 


\section{Results and Discussion}

\section{Shelf life of carrier based biofertilizer}

Rhizobium - carrier based biofertilizer was collected on August 15, 2015 from ABT Rajendranagar, (Mfg date - Aug 1 2015). The initial population of Rhizobium on YEMA with Congo red medium was4.6 x $10^{7} \mathrm{CFU}$ g ${ }^{1}$.The viability of microorganisms were evaluated on monthly intervals upto January. The microbial analysis revealed that there was a decline in the population of Rhizobium from August $\left(4.6 \times 10^{7} \mathrm{CFU} \mathrm{g}^{-1}\right)$ to January $(3.2 \mathrm{x}$ $10^{5} \mathrm{CFU} \mathrm{g} \mathrm{g}^{-1)}$. Level of contaminants observed were $1.5 \times 10^{5}, 1.6 \times 10^{5}, 1.8 \times 10^{5}$ during last three months i.e. November, December and January. The quality was not good as prescribed population $\left(5 \times 10^{7} \mathrm{CFU} \mathrm{g}^{-1}\right)$ was not found even within one month (Table 1).

Rhizobium - carrier based biofertilizer was collected on July 29, 2015 from K.N Biosciences (Mfg date - July 20 2015). The initial population of Rhizobiumwas $1.5 \times 10^{6}$ CFU g ${ }^{-1}$ onYEMAwith Congo red medium. The viability of microorganisms were evaluated on monthly intervals upto January. The microbial analysis revealed that there was a decline in the population of Rhizobium from August $\left(1.5 \times 10^{6} \mathrm{CFU} \mathrm{g}^{-1)}\right.$ to January $(4.5 \mathrm{x}$ $\left.10^{3} \mathrm{CFU} \mathrm{g}{ }^{-1}\right)$. Level of contaminants observed were1.7 $\times 10^{5}, 1.8 \times 10^{5}$ during last two months i.e December and January. The quality was not good as prescribed population was not found even within one month.

Rhizobium - carrier based biofertilizer was collected on July 29, 2015 from Pratista Biofertilizers (Mfg date - July 15, 2015). The initial population of Rhizobium on YEMA with Congo red medium was $1.59 \times 10^{8} \mathrm{CFU}$ $\mathrm{g}^{-1}$. The viability of microorganisms was evaluated on monthly intervals up to January. The microbial analysis revealed that there was a decline in the population of Rhizobium from
August $\left(1.59 \times 10^{8} \mathrm{CFU} \mathrm{g}^{-1}\right)$ to January $(4.0 \mathrm{x}$ $\left.10^{5} \mathrm{CFU} \mathrm{g}^{-1}\right)$. Level of contaminants observed were $1.8 \times 10^{5}, 2.0 \times 10^{5}$ during last two months i.e. December and January. The biofertilizer retained desired population till four months, but there was considerable contamination in second month (September). Hence biofertilizer quality was retained upto two months (Fig. 1).

Rhizobium - carrier based biofertilizer was collected on August 15, 2015 from ARS Amaravathi, ANGRAU (Mfg date - July 29, 2015). The initial population of Rhizobium found on YEMA with Congo red medium was $5.4 \times 10^{8}$ CFU $\mathrm{g}^{-1}$. The viability of microorganisms were evaluated on monthly intervals upto January. The microbial analysis revealed that there was a decline in the population of Rhizobiumf rom August $(5.4 \mathrm{x}$ $\left.10^{8} \mathrm{CFU} \mathrm{g}^{-1}\right)$ to January $\left(7.4 \times 10^{5} \mathrm{CFU} \mathrm{g} \mathrm{g}^{-1}\right)$. After five months i.e. in January month microbial count was reduced to $7.4 \times 10^{5} \mathrm{CFU}$ $\mathrm{g}^{-1}$. The biofertilizer retained desired population till four months and there was no contamination. Hence shelf life of biofertilizer was retained upto four months.

PSB - carrier based biofertilizer was collected on August 15, 2015 from ABT Rajendranagar, (Mfg date - August 1, 2015). The initial population of PSB found on Pikovskaya's Agarwas $4.7 \times 10^{7} \mathrm{CFU} \mathrm{g}{ }^{-1}$.The viability of microorganisms were evaluated on monthly intervals upto January. The microbial analysis revealed that there was a decline in the population of PSB from August $\left(4.7 \times 10^{7} \mathrm{CFU} \mathrm{g}^{-1}\right)$ to January $\left(2.5 \times 10^{4} \mathrm{CFU}\right.$ $\mathrm{g}^{-1)}$. After five months microbial count was reduced to $2.5 \times 10^{4} \mathrm{CFU} \mathrm{g}^{-1}$. The biofertilizer retained desired population till two months and there was no contamination. Hence shelf life of biofertilizer was retained upto two months. PSB - carrier based biofertilizer was collected on July 29, 2015 from K.N Biosciences (Mfg date - July 20, 2015). The 
initial population of PSB found on Pikovskaya's Agar was $3.8 \times 10^{7} \mathrm{CFU} \mathrm{g}^{-1}$ The viability of microorganisms were evaluated on monthly intervals upto January. The microbial analysis revealed that there was a decline in the population of PSB from August $\left(3.8 \times 10^{7} \mathrm{CFU} \mathrm{g}^{-1}\right)$ to January $\left(5.0 \times 10^{4} \mathrm{CFU}\right.$ $\mathrm{g}^{-1)}$. After five months microbial count was reduced to $5.0 \times 10^{4} \mathrm{CFU} \mathrm{g}^{-1}$ and no contamination was observed. The quality was not good as prescribed population was not found even within one month.

PSB - carrier based biofertilizer was collected on July 29, 2015 from pratista Biofertilizers (Mfg date - July 15, 2015) (Fig. 2). The initial population of PSB on Pikovskaya's Agar was $3.2 \times 10^{8} \mathrm{CFU} \mathrm{g}^{-1}$. The viability of microorganisms were evaluated on monthly intervals upto January. The microbial analysis revealed that there was a decline in the population of PSB from August $\left(3.2 \times 10^{8}\right.$ CFU g $\left.{ }^{-1}\right)$ to January $\left(3.0 \times 10^{4} \mathrm{CFU} \mathrm{g}^{-1}\right)$. After five months microbial count was reduced to
$3.0 \times 10^{4} \mathrm{CFU} \mathrm{\textrm {g } ^ { - 1 }}$. The biofertilizer retained desired population till two months and there was no contamination. Hence biofertilizer quality was retained upto two months.

PSB - carrier based biofertilizer was collected on August 15, 2015 from ARS Amaravathi ANGRAU (Mfg date - July 29, 2015).The initial population of PSB found on Pikovskaya's Agar was $7.4 \times 10^{8} \mathrm{CFU} \mathrm{g}^{-1}$. The viability of microorganisms were evaluated on monthly intervals upto January. The microbial analysis reveals that there was a decline in the population of PSB from August (7.4 x $\left.10^{8} \mathrm{CFU} \mathrm{g}^{-1}\right)$ to January $\left(7.8 \times 10^{5} \mathrm{CFU}\right.$ $\left.\mathrm{g}^{-1}\right)$. After five months microbial count has reduced to $7.8 \times 10^{5} \mathrm{CFU} \mathrm{g}^{-1}$ and no contamination was observed. The biofertilizer retained desired population till four months and there was no contamination. Hence shelf life of biofertilizer was retained upto four months.

Fig.1 Evaluation of shelf life of Rhizobium carrier based biofertilizer from different production centers

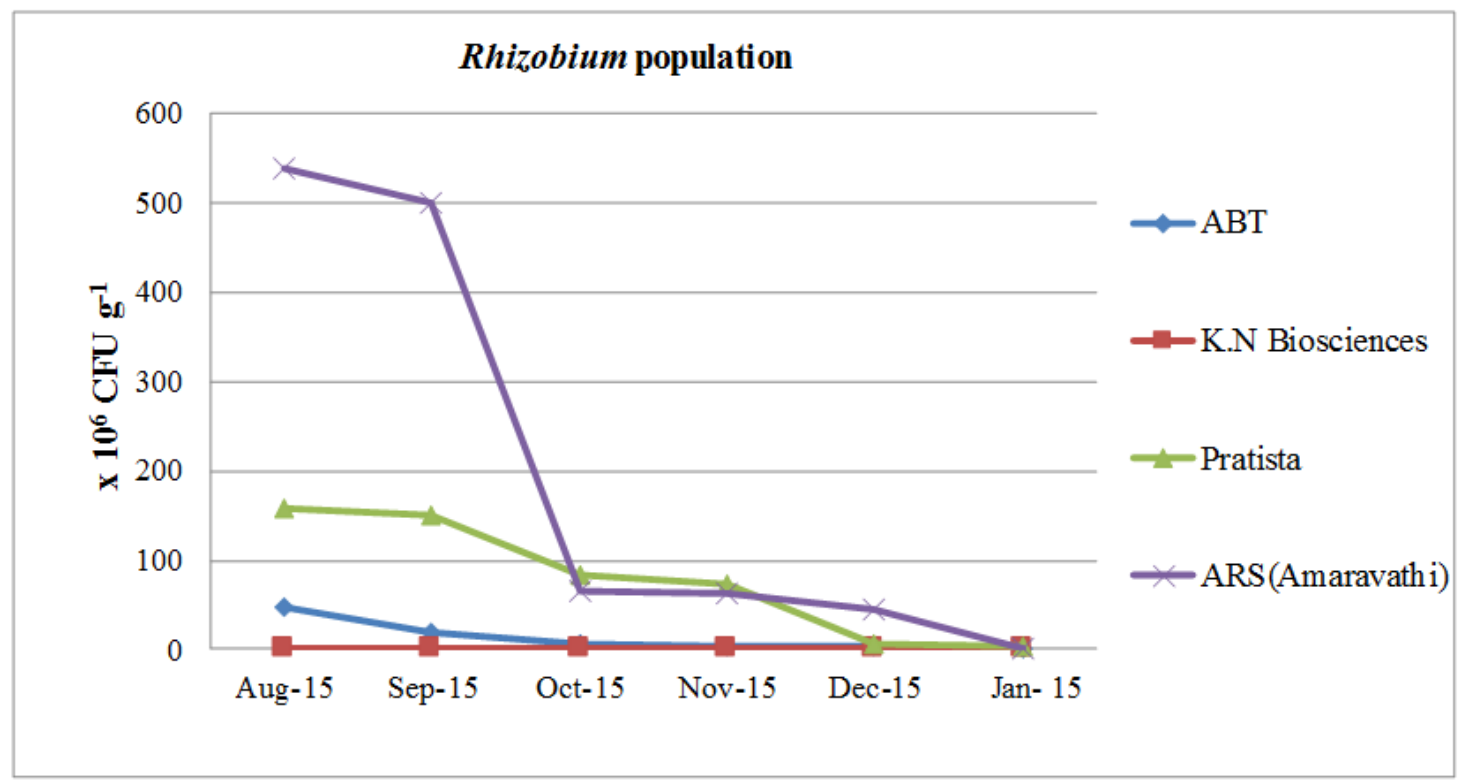




\section{Carrier based Biofertilizers}

\begin{tabular}{|l|l|l|}
\hline $\mathbf{1}$ & Rhizobium & $\begin{array}{l}\text { Agri. Biotech Foundation, K.N Biosciences (India).pvt.ltdPratista t } \\
\text { Biofertilizers, Agricultural Research Station. }\end{array}$ \\
\hline $\mathbf{2}$ & PSB & $\begin{array}{l}\text { Agri. Biotech Foundation, K.N Biosciences (India).pvt.ltd,Pratista t } \\
\text { Biofertilizers, Agricultural Research Station. }\end{array}$ \\
\hline
\end{tabular}

Table.1 Shelf life of carrier based Rhizobium and PSB Biofertilizers from different production centres

\begin{tabular}{|c|c|c|c|c|c|c|c|}
\hline \multirow[t]{2}{*}{ ABT(PJTSAU) } & Rhizobium & $4.6 \times 10^{7} \mathrm{CFU} \mathrm{g}^{-1}$ & $2.0 \times 10^{7} \mathrm{CFU} \mathrm{g}^{-1}$ & $5.9 \times 10^{6} \mathrm{CFU} \mathrm{g}^{-1}$ & $4.3 \times 10^{6} \mathrm{CFU} \mathrm{g}^{-1}$ & $4.0 \times 10^{6} \mathrm{CFU} \mathrm{g}^{-1}$ & $3.2 \times 10^{5} \mathrm{CFU} \mathrm{g}^{-1}$ \\
\hline & PSB & $5.0 \times 10^{7} \mathrm{CFU} \mathrm{g}^{-1}$ & $3.2 \times 10^{7} \mathrm{CFU} \mathrm{g}^{-1}$ & $6.9 \times 10^{6} \mathrm{CFU} \mathrm{g}^{-1}$ & $6.4 \times 10^{5} \mathrm{CFU} \mathrm{g}^{-1}$ & $4.5 \times 10^{5} \mathrm{CFU} \mathrm{g}^{-1}$ & $2.5 \times 10^{4} \mathrm{CFU} \mathrm{g}^{-1}$ \\
\hline K.N Biosciences & Rhizobium & $1.5 \times 10^{6} \mathrm{CFU} \mathrm{g}^{-1}$ & $3.2 \times 10^{5} \mathrm{CFU} \mathrm{g}^{-1}$ & $2.5 \times 10^{5} \mathrm{CFU} \mathrm{g}^{-1}$ & $2.0 \times 10^{5} \mathrm{CFU} \mathrm{g}^{-1}$ & $2.0 \times 10^{4} \mathrm{CFU} \mathrm{g}^{-1}$ & $4.5 \times 10^{3} \mathrm{CFU} \mathrm{g}^{-1}$ \\
\hline \multirow{2}{*}{$\begin{array}{l}\text { Pratista } \\
\text { Biofertilizers }\end{array}$} & Rhizobium & $1.59 \times 10^{8} \mathrm{CFU} \mathrm{g}^{-1}$ & $1.5 \times 10^{8} \mathrm{CFU} \mathrm{g}^{-1}$ & $8.2 \times 10^{7} \mathrm{CFU} \mathrm{g}^{-1}$ & $7.2 \times 10^{7} \mathrm{CFU} \mathrm{g}^{-1}$ & $3.6 \times 10^{6} \mathrm{CFU} \mathrm{g}^{-1}$ & $4.0 \times 10^{5} \mathrm{CFU} \mathrm{g}^{-1}$ \\
\hline & PSB & $3.2 \times 10^{8} \mathrm{CFU} \mathrm{g}^{-1}$ & $2.8 \times 10^{7} \mathrm{CFU} \mathrm{g}^{-1}$ & $1.1 \times 10^{7} \mathrm{CFUg}^{-1}$ & $4.9 \times 10^{6} \mathrm{CFU} \mathrm{g}^{-1}$ & $3.4 \times 10^{5} \mathrm{CFU} \mathrm{g}^{-1}$ & $3.0 \times 10^{4} \mathrm{CFU} \mathrm{g}^{-1}$ \\
\hline ARA(Amaravathi) & PSB & $7.4 \times 10^{8} \mathrm{CFU} \mathrm{g}^{-1}$ & $5.4 \times 10^{8} \mathrm{CFU} \mathrm{g}^{-1}$ & $6.8 \times 10^{7} \mathrm{CFU} \mathrm{g}^{-1}$ & $5.4 \times 10^{7} \mathrm{CFU} \mathrm{g}^{-1}$ & $5.5 \times 10^{6} \mathrm{CFU} \mathrm{g}^{-1}$ & $7.8 \times 10^{5} \mathrm{CFU} \mathrm{g}^{-1}$ \\
\hline
\end{tabular}


Fig.2 Evaluation of shelf life of PSB carrier based biofertilizer from different production centers

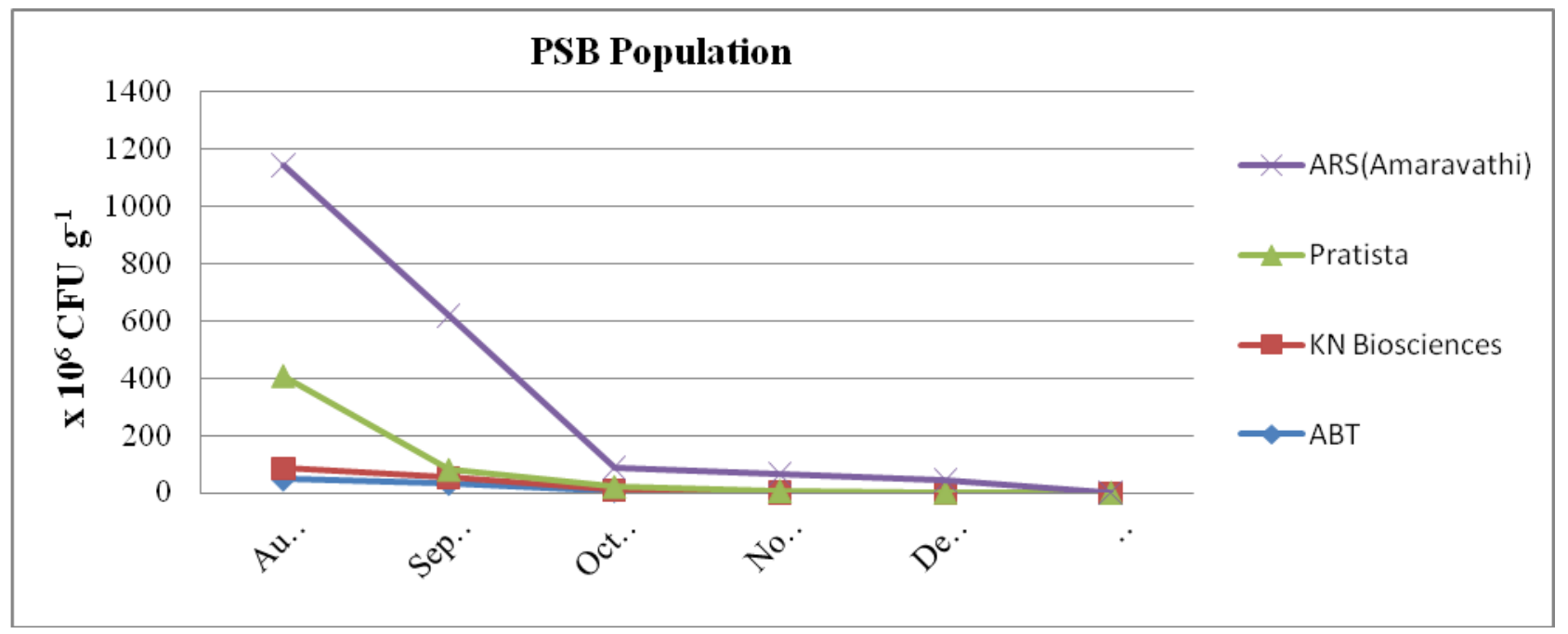

Shelf life of liquid based Biofertilizers

Rhizobium - liquid based biofertilizer was collected on July 29, 2015 from K.N Biosciences (Mfg date - July 20, 2015). The initial population of Rhizobium on YEMA with Congo red medium was $1.2 \times 10^{7} \mathrm{CFU} \mathrm{g}^{-1}$. The viability of microorganisms was evaluated on monthly intervals up to January. The microbial analysis revealed that there was a decline in the population of Rhizobium from August $\left(1.2 \times 10^{7} \mathrm{CFU} \mathrm{g}^{-1}\right)$ to January $(1.2 \mathrm{x}$ $\left.10^{4} \mathrm{CFU} \mathrm{g}{ }^{-1}\right)$. After five months i.e. in January month microbial count was reduced to $1.2 \mathrm{x}$

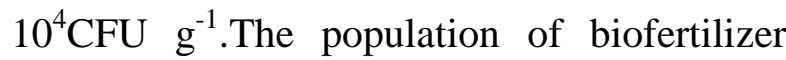
was less than the prescribed population standards. Hence the quality of biofertilizer was not good.

Rhizobium - liquid based biofertilizer was collected July 29, 2015 from Pratista Biofertilizers (Mfg date - July 15, 2015). The initial population of Rhizobium found on YEMA with Congo red medium was $2.6 \times 10^{8}$ $\mathrm{CFU} \mathrm{^{-1 }}$. The viability of microorganisms was evaluated on monthly intervals up to January. The microbial analysis reveals that there was a decline in the population of Rhizobium from August $\left(2.6 \times 10^{8} \mathrm{CFU} \mathrm{g}{ }^{-1}\right)$ to January $(7.4 \mathrm{x}$ $10^{5} \mathrm{CFU} \mathrm{g}^{-1}$ ). After five months i.e. in January month microbial count has reduced to $7.4 \mathrm{x}$ $10^{5} \mathrm{CFU} \mathrm{g}^{-1}$. The biofertilizer retained desired population till six months and there was no contamination. Hence quality of biofertilizer was retained upto six months.

Rhizobium - liquid based biofertilizer was collected on August 15, 2015 from ARS Amaravathi ANGRAU (Mfg date - July 29, 2015). The initial population of Rhizobium was $8.4 \times 10^{8} \mathrm{CFU} \mathrm{g}^{-1}$ on YEMA with Congo red medium. The viability of microorganisms were evaluated on monthly intervals upto January. The microbial analysis reveals that there was a decline in the population of Rhizobium from August $\left(6.4 \times 10^{8} \mathrm{CFU} \mathrm{g}^{-1}\right)$ to January $\left(8.4 \times 10^{5} \mathrm{CFU} \mathrm{g}{ }^{-1}\right)$. After five months i.e. in January month microbial count was reduced to $8.4 \times 10^{5} \mathrm{CFU} \mathrm{g}{ }^{1}$. The biofertilizer retained desired population till four months and there was no contamination. Hence quality of biofertilizer was retained up to four months.

PSB - liquid based biofertilizer was collected on July 29, 2015 from K.N Biosciences (Mfg date - July 20, 2015). The initial population of PSB was found on Pikovskaya's Agar was 2.6

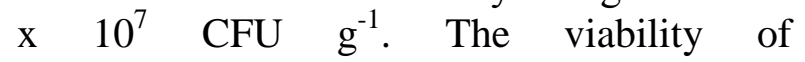
microorganisms were evaluated on monthly 
intervals upto January. The microbial analysis revealed that there was a decline in the population of PSB from August $\left(2.6 \times 10^{7}\right.$ CFU g $\left.{ }^{-1}\right)$ to January $\left(2.5 \times 10^{5} \mathrm{CFU} \mathrm{g}^{-1}\right)$. After five months microbial count has reduced to $2.5 \times 10^{5} \mathrm{CFU} \mathrm{g}^{-1}$. The biofertilizer retained desired population till three months and there was no contamination. Hence quality of biofertilizer was retained upto three months.

PSB - liquid based biofertilizer was collected July 29, 2015 from pratista Biofertilizers (Mfg date - July 15, 2015). The initial population of PSB was taken on Pikovskaya's Agar was $2.6 \times 10^{7} \mathrm{CFU} \mathrm{g}^{-1}$. The viability of microorganisms were evaluated on monthly intervals upto January. The microbial analysis revealed that there was a decline in the population of PSB from August $\left(2.6 \times 10^{7}\right.$ CFU g $\left.{ }^{-1}\right)$ to January $\left(2.5 \times 10^{5} \mathrm{CFU} \mathrm{g}^{-1}\right)$. After five months microbial count was reduced to $2.5 \times 10^{5} \mathrm{CFU} \mathrm{g}^{-1}$. The biofertilizer retained desired population till three months and there was no contamination. Hence quality of biofertilizer was retained upto three months.

PSB - liquid based biofertilizer was collected on August 15, 2015 from ARS Amaravathi ANGRAU (Mfg date - July 29, 2015). The initial population of PSB was found on Pikovskaya's Agar was 5.4 x $10^{8} \mathrm{CFU} \mathrm{g}^{-1}$. The viability of microorganisms were evaluated on monthly intervals upto January. The microbial analysis revealed that there was a decline in the population of PSB from August $\left(5.4 \times 10^{8} \mathrm{CFU} \mathrm{g}^{-1}\right)$ to January $(7.1 \mathrm{x}$ $\left.10^{5} \mathrm{CFU} \mathrm{g}^{-1}\right)$. After five months microbial count was reduced to $7.1 \times 10^{5} \mathrm{CFU} \mathrm{g}^{-1}$. The biofertilizer retained desired population till five months and there was no contamination. Hence quality of biofertilizer was retained upto five months.

Different carrier based biofertilizers are brought from different firms for evaluation of their quality. In case of carrier based
Biofertilizers was estimated. In case of liquid based Biofertilizers, population of beneficial bacteria was estimated. The shelf life of biofertilzers was estimated using suitable media for viable count. Microbial population of beneficial bacteria was monitored in liquid and carrier based Biofertilizers at monthly intervals.

In carrier based Biofertilizers, the quality was too low, moisture content was high and decrease in count was more. The shelf life of biofertlizers from ARS (Amaravathi) was good followed by ABT and Pratista Biofertilizers. Use of Biofertilizers within four months from manufactured date is beneficial as viable count was observed more.

\section{References}

Ashrafi V, Seiedi MN (2011). Influence of different plant densities and plant growth promoting rhizobacteria (PGPR) on yield and yield attributes of Corn (Zea mays L.). Recent Res. Sci. Technol., 3(1): 63- 66.

Bhattacharyya, P. and Kumar, R. (2002). Liquid biofertiliser - Current knowledge and future prospect. Proceedings of the National Seminar on Development and use of Biofertilizers, biopesticides and organic manures, November 10-12, 2000, B.C.K.V., Kalyani, Nadia, West Bengal. pp 10 - 21.

Heidari G.R., Mohammadi K., Ghalavand A., Aghaalikhani M and Sohrabi Y. 2011. Introducing the sustainable soil fertility system for chickpea (Cicer arietinum L.). African Journal of Biotechnology. 10(32): 6011-6020.

Kumaresan, G and Reetha, D. 2011. Survival of Azospirillum brasilense in liquid formulation amended with different chemical additives. Journal of Phytology. 3(10): 48-51.

Liu, J., Tian, S., Li, B and Qin, G. 2009. 
Enhancing viability of two biocontrol yeasts in liquid formulation by applying sugar protectant combined with antioxidant. Biocontrol. 54: 817-824.

Subba Rao, N.S., 1999. The rhizosphere and the phyllosphere, In: Soil Microbiology, 4 th edition, p: 85. Science Publishers, Inc., Enfield, New Hampshire, UK.

Vlassak, K.L., Van, H and Duchateau, L. 1992. Isolation and characterization of fluorescent Pseudomonas associated with the roots of rice and banana grown in Srilanka. Plant and soil. 145: 51-63.

Wu, S.C., Z.H. Cao., Z.G. Li., K.C. Cheung and M.H. Wong. 2005. Effects of biofertilizer containing $\mathrm{N}$-fixer, $\mathrm{P}$ and $\mathrm{K}$ solubilizers and AM fungi on maize growth: a greenhouse trial. Geoderma. $125: 155-166$.

\section{How to cite this article:}

Bhavya, K., R. Subhash Reddy, S. Triveni, K. Damodara Chari and Nagaraju, Y. 2017. Study of Shelflife of Carrier Biofertilizers from Different Production Centers. Int.J.Curr.Microbiol.App.Sci. 6(6): 1776-1783. doi: https://doi.org/10.20546/ijcmas.2017.606.206 